\title{
UN MODELO DE ANÁLISIS SINTÁCTICO, PASO A PASO
}

\author{
J. Javier Mangado Martínez \\ Universidad de La Rioja
}

\begin{abstract}
RESUMEN. En este artículo el autor, con más de veinticinco años de experiencia enseñando sintaxis en la Universidad, explica el método que sigue en su práctica docente del análisis sintáctico. Lo hace paso a paso, es decir, justificando cada una de las sucesivas fases, y reflexiona abiertamente sobre los principios epistemológicos y didácticos en los que se basa su actitud. Con el fin de consolidar la teoría al respecto, la aplica de manera sistemática al análisis concreto de una oración compleja.
\end{abstract}

ABSTRACT. In the present article the author, with over twenty-five years' experience in teaching syntax at a university level, explains the method followed in his teaching practice of syntax analysis. He does so step by step, that is, justifying each one of the successive stages, and he openly reflects on the epistemological and didactic principles involved in his approach. With the aim of consolidating the theory at issue he systematically applies it to the specific analysis of a complex sentence.

\section{Introducción}

La práctica del análisis sintáctico mediante diagramas constituye un procedimiento arraigado en la didáctica de la gramática. No es de extrañar dado que éstos, por una parte, poseen un relativo carácter lúdico y, por otra, obligan a quien los elabora a pensar (debe decidir continuamente cuál es la aplicación más pertinente de la teoría lingüística que conoce). Los hay de muy diversos tipos: de casillas, de bandejas, en estema, arbóreos... Optar por uno u otro método depende, además de la formación de cada cual y de sus gustos personales, de la cantidad de información que se quiera y se pueda transmitir; como afirman Guillermo Rojo y Tomás Jiménez Juliá, "las representaciones [del análisis sintáctico] son adecuadas o no en la medida en que permiten representar lo que la teoría dice" ${ }^{\prime 1}$.

1. ROJO, G. y JIMÉNEZ JULIÁ, T., Fundamentos del análisis sintáctico funcional. Universidad de Santiago de Compostela, 1989, p. 70. El capítulo 3 de esta obra (pp. 63-88) está dedicado a un repaso crítico de los métodos más utilizados en la representación del análisis sintáctico; otro repaso crítico de gran interés puede verse en el excelente libro, recentísimo, de Salvador Gutiérrez, Manuel Iglesias y Carmen Lanero Análisis sintáctico 1, Madrid, Anaya, 2002, pp. 26-31. 
En el presente trabajo pretendo explicar, paso a paso, un tipo de análisis sintáctico y su plasmación gráfica: el que vengo practicando y enseñando a mis alumnos de sintaxis durante más de veinticinco años de docencia universitaria, período en el que, naturalmente, se ha ido enriqueciendo por afuera y por adentro con diversas aportaciones sucesivas que lo han afianzado ${ }^{2}$.

Como puede deducirse fácilmente de la bibliografía que acabo de citar en nota, la doctrina lingüística que informa mi concepción sintáctica se fundamenta en el estructuralismo funcionalista. No obstante, en la aplicación de este cuerpo doctrinal podrá encontrarse algún detalle de corte generativista y alguna contribución personal reinterpretadora.

Se trata de un análisis desarrollado mediante diagrama en "bandejas" por considerarlo el sistema más sencillo, más versátil y el que de modo más natural y práctico admite la precisión de las anotaciones morfofuncionales necesarias, por largas que éstas sean. No exige destrezas de diseño especiales y permite su adecuación a cualquier nivel de enseñanza, siempre que quien lo practique (claro está) posea la formación lingüística imprescindible.

He elegido para inferirlo una oración compuesta a cuya complejidad relativa se irá llegando poco a poco partiendo de lo más elemental. Cada profesor sabrá a qué estadio del proceso no pueden llegar aún sus alumnos y escoger, en consecuencia, oraciones más sencillas. El método en sí, naturalmente, no varía. La frase en cuestión podía leerse hace unos años en todos los centros sanitarios públicos de España: La libertad de fumar termina donde empieza el derecho de los demás a respirar aire puro.

Una última aclaración previa: no es mi intención pontificar ni dogmatizar, sino, simplemente, ofrecer un método de análisis contrastado por una larga experiencia con el único fin de que pueda ser adoptado (o adaptado) total o parcialmente por quien lo considere oportuno para sus intereses personales o profesionales.

Entremos ya al meollo.

\footnotetext{
2. De algunas de estas aportaciones ni siquiera soy consciente. Sí lo soy, por supuesto, de la mayoría. Haciendo una selección de selecciones de lo más restrictiva (no procede aquí resultar prolijo), debo destacar las obras de Emilio Alarcos Llorach, sobre todo los Estudios de gramática funcional del español (Madrid, Gredos, 1980 -3a ed.-) y la Gramática de la lengua española (Madrid, Espasa Calpe, 1994); la Gramática funcional del español de César Hernández (Madrid, Gredos, 1984) y la Morfosintaxis del español actual de Ernesto Carratalá (Barcelona, Labor Universitaria, 1980), libro éste que selecciono porque su publicación hizo que me replanteara varias cuestiones de gran interés. En el aspecto concreto teórico-práctico del análisis sintáctico, quiero manifestar la enorme influencia que produjo en mí la lectura, allá por los años setenta, del opúsculo de J. García López y C. Pleyán Introducción en la metodología del análisis estructural (Barcelona, Teide, 1969), y lo que me hizo pensar el estudio de la obra de Jesús Tusón Teorías gramaticales y análisis sintáctico (Barcelona, Teide, 1980), libro clarificador, y aconsejable, donde los haya. De ambos se alimenta, sobre todo, el modelo que voy a exponer aquí. Una publicación práctica muy recomendable, con muchas oraciones muy bien analizadas (en diagramas arbóreos), que sigue las pautas de Jesús Tusón, hallará el lector interesado en el trabajo de Argimiro Boix y seis profesores más Práctica del análisis sintáctico (Barcelona, PPU, 1984; la 2a edición, corregida y aumentada, es de 1988). De igual fiabilidad goza el libro de Leonardo Gómez Torrego Teoría y práctica de la sintaxis (Madrid, Alhambra, 1985), sin diagramas, y su recentísimo Análisis sintáctico. Teoría y práctica (Madrid, SM, 2002), en "casillas".
} 


\section{Análisis}

\section{PASO 1}

Se escribe la frase que se va a analizar separando bien las palabras que la componen. Téngase en cuenta que las palabras gramaticales no siempre coinciden con las unidades gráficas: a menudo varias palabras gráficas se corresponden con una sola gramatical o, viceversa, una sola palabra gráfica consta de varias gramaticales. Al primer caso pertenecen, por ejemplo, las formas compuestas de los verbos (han venido, habías comido, habremos hablado...), las perífrasis verbales (vamos a llegar, volví a repetir, venimos insistiendo...), o las diversas locuciones: verbales (tener en cuenta, echar de menos...), adverbiales (sin embargo, a tontas y a locas...), prepositivas (de entre, frente a...), conjuntivas (sino que, siempre y cuando, con tal que...), entre otras. Al segundo corresponden, verbi gratia, las contracciones al, del o las formas verbales con enclítico (dármelo, mostrándoselas, dile...).

Una forma sencilla y satisfactoria (que por eso adopto) de señalar los límites de las unidades mínimas léxico-sintácticas desde las que partimos para construir nuestro análisis consiste, simplemente, en subrayarlas. Así, si queremos analizar la oración Se dice que al verla rompió a llorar amargamente, la prepararemos del siguiente modo:

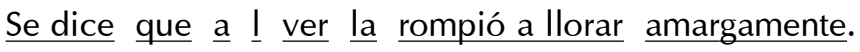

Puede ocurrir que en la escritura normal de una palabra gramatical compleja se injiera alguna otra; es decir, que la unidad léxico-semántica analizable se presente de manera discontinua. En tal caso, la discontinuidad puede expresarse uniendo la línea subrayada de los elementos fragmentados mediante puntos o rayas intermitentes que pasen justo por la zona de las palabras interpoladas. El subrayado de éstas ha de hacerse, en consecuencia, a otro nivel espacial. He aquí una muestra:

Me arrepentí de habér se lo dicho entonces.

También puede indicarse quebrando la línea subrayadora de manera que salve por encima los elementos intercalados:

Me arrepentí de habér $\underline{\text { se }} \underline{\text { lo }}$ dicho entonces.

No soy partidario de alterar el orden de un texto, sino de respetarlo escrupulosamente, entre otras razones porque, al manipularlo, a menudo se incurriría en artificioso desorden ( ${ }^{*}$ Me arrepentí de haber dicho se lo entonces o *Me arrepentí de se lo haber dicho entonces ${ }^{3}$ y se acabaría abusando del procedimiento subjetivo hasta desfigurar $y$ tergiversar el enunciado ${ }^{4}$.

3. Utilizo en este trabajo el asterisco $\left(^{*}\right)$ colocado en la parte superior y a la izquierda de una secuencia lingüística para expresar que ésta es agramatical, artificial o incorrecta.

4. No obstante, hay ocasiones en que es evidente que el cambio de orden resulta inocuo y facilita la representación gráfica: reescribir, por ejemplo, Debió haberlo contado como Lo debió haber contado. 
Ninguno de estos pequeños obstáculos se da en la oración que vamos a analizar completamente; en ella las palabras gráficas coinciden con las gramaticales:

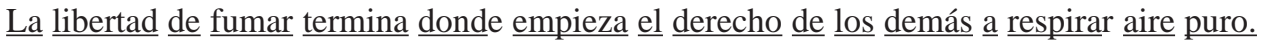

Un consejo práctico externo: conviene acostumbrar a los alumnos a que elaboren sus análisis sintácticos escribiendo los textos en la hoja de forma apaisada. Eso les proporcionará cómoda holgura y evitará confusiones enojosas (un lío de rayas) por partir la frase y escribirla en varias líneas. Si la oración para analizar es tan larga que desborda los límites de la página aun en sentido apaisado, resulta mucho más conveniente añadir (pegar, grapar) otra hoja y seguir en el mismo sentido que romper la frase sucesivamente en la misma página fomentando marañas e incomodidades evitables con facilidad. Obrar como aconsejo allanará el proceder del alumno y aclarará la corrección del profesor; a ambos les ahorrará esfuerzos inútiles.

\section{PASO 2}

Una vez que hemos aislado las unidades léxico-sintácticas mínimas (los ladrillos con los que vamos a construir el edificio), nuestra tarea consiste en ir engarzándolas gradualmente para formar los sucesivos sintagmas; es decir, las unidades sintácticas de rango inmediatamente superior. Para ello, previamente, tendremos que ir preguntándonos si cada una de las palabras gramaticales que hemos delimitado son nucleares o marginales y anotar la respuesta debajo de cada una: "núc." (núcleo) en el primer caso; "ady." (adyacente) en el segundo. Puntualizaciones: 1) Aunque no cabe duda de que son adyacentes, suele especificarse la subclase de los determinantes, y yo mantengo esa costumbre ("det."). 2) A otro nivel se encuentran las categorías de relación: preposiciones y conjunciones. A las primeras no les doy un nombre distinto ("prep."), entre otras razones por coherencia didáctica con la etiqueta "sintagma preposicional"; mientras que, por lo que respecta a las segundas, distingo entre conectores ("con.") -las coordinantes: $y, o$, pero...- y transpositores ("tr.") -las subordinantes: que, si, aunque...-. 3) Cuando un sintagma está constituido por una sola palabra, anoto directamente la función sintáctica (O.D., O.I., etc.): mi mente rechaza llamar "núcleo" a un elemento único (de la misma manera que se niega a admitir referirse al único árbol de un patio como su "árbol principal"). He aquí un ejemplo que contiene todos los membretes comentados:

Espero que el amigo de Luis venga muy pronto y nos dé su impresión personal

Pero vayamos a nuestra frase y hagamos en ella las primeras anotaciones:

La libertad de fumar termina donde empieza el derecho de los demás a respirar aire puro

$$
\text { núc. } \frac{\text { ady. }}{}
$$

Como se ve, comienzo por el final; es decir, opero de derecha a izquierda. Esta manera de proceder llama la atención de muchos. Me parece la más lógica y didáctica porque asegura la práctica del método inductivo, método con el que se ha de 
abordar el análisis sintáctico y, sobre todo, su enseñanza. Por otra parte, es como empezar a desmontar una máquina o un mueble por las últimas piezas que se colocaron en su montaje (lo normal, ¿no?).

El sustantivo aire funciona como núcleo del adjetivo puro, su adyacente por lo tanto (respirar aire/*respirar puro). Estos rótulos ("núc." / "ady.") expresan suficientemente las relaciones de dependencia: cuál es la constante y cuál la variable. No obstante, considero conveniente realzarlas, en todas las unidades sintácticas del análisis, mediante el refuerzo didáctico de flechas cuya punta señale el elemento nuclear, y la cola, el marginal. Se trata de un sistema visual muy eficaz para identificar y delimitar los diversos sintagmas: éstos están constituidos por el conjunto de las unidades que en el análisis de la frase se ven asociadas por las flechas.

¿Hay en el texto alguna palabra o elemento más que dependa del núcleo "aire"? No; así que ya tenemos identificado nuestro primer sintagma: "aire puro".

\section{PASO 3}

Lo delimitamos encerrándolo en la "bandeja" correspondiente, anotamos debajo su nombre y su función, y reforzamos la expresión de ésta mediante el sistema de flechas explicado:

La libertad de fumar termina donde empieza el derecho de los demás a respirar aire puro

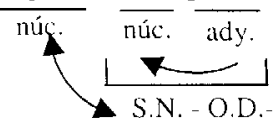

(Recuérdese que los sintagmas reciben el nombre de su núcleo: lo llamamos nominal (S.N.) si ése es un sustantivo; adjetival (S. adj.), si adjetivo; verbal (S.V.), si verbo; adverbial (S. adv.), si adverbio. La excepción la constituye el sintagma preposicional (S. prep. $)^{5}$; por tratarse de una construcción exocéntrica, le da nombre el enlace que la introduce). Dado que en aire puro el núcleo pertenece a la categoría de los sustantivos, aire puro forma un S.N. ¿Qué función desempeña? La de objeto directo (O.D.): puede conmutarse por uno de los pronombres átonos de acusativo (lo, la, los, las), en este caso lo por ser aire masculino y singular $\left(\right.$ a respirarlo) ${ }^{6}$. La conmutación puede

5. Mantengo esta entidad sintagmática, integrada por una preposición + su término, por razones didácticas. Los gramáticos suelen prescindir de ella. El propio Alarcos diría que en la oración Lo decidieron en su casa el S.N. su casa desempeña la función de complemento circunstancial (o aditamento) mediante el "índice funcional" en. Nosotros indicaríamos que en su casa es un sintagma preposicional (constituido por la preposición en + el S.N. su casa) que cumple la función de complemento circunstancial. Dos caminos diferentes que, sin embargo, conducen a la misma meta.

6. La otra prueba concluyente para detectar el O.D., la transformación a pasiva (según la cual cumplirá la función de O.D. en una estructura activa el sintagma susceptible de funcionar como sujeto en la correspondiente estructura pasiva, que debe ser gramatical y sustancialmente sinónima), resulta aquí inconveniente por originar una secuencia inusitada y artificial ( $^{*} . .$. el derecho de los demás a ser respirado aire puro), lo que suele ocurrir en las construcciones no absolutas integradas por proposiciones transitivas de infinitivo, como ésta, y de gerundio (Lo vi leyendo un libro / * Lo vi siendo leído un libro). Puede salvarse este obstáculo convirtiendo la proposición en una oración, con verbo en forma personal, que nos posibilite la transformación expedita a pasiva: Los demás respiran aire puro / Aire puro es respirado por los demás. 
reflejarse, si se quiere, en el diagrama del análisis. Ya que corresponde al eje paradigmático, es decir, se trata de la relación con un elemento no presente en la estructura que se analiza, ha de figurar fuera de ésta. Se expresa bien con una "bandeja" invertida que delimite por arriba el tramo conmutado y cuya línea superior aparezca interrumpida por el elemento por el que se conmuta:

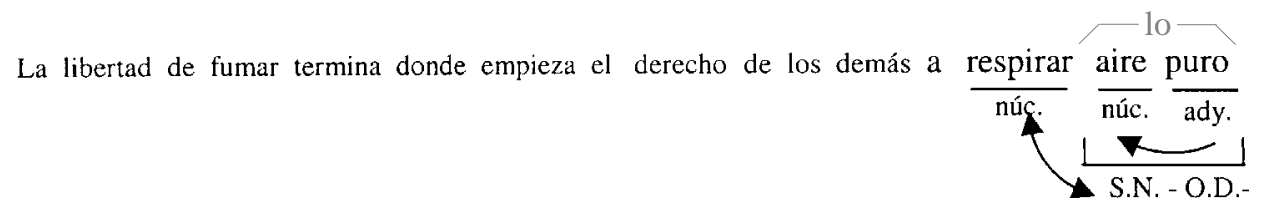

Este eje paradigmático conviene discriminarlo gráficamente de alguna manera; con un color diferente, por ejemplo (aquí lo hemos señalado atenuándolo en gris).

Si bien todo O.D. presupone un verbo transitivo del que depender, no es menos obvio que un verbo transitivo, como tal, requiere prolongarse en un O.D.; es decir, verbo transitivo y O.D. están doblemente implicados, o sea, en relación de interdependencia. Eso queremos expresar con la flecha de doble punta que enlaza este par en nuestro análisis.

¿Hay en el texto algún elemento que dependa de ese bloque transitivo? ¿No? Pues demos el paso siguiente.

\section{PASO 4}

Acotamos con una "bandeja" el sintagma resultante (respirar aire puro) y anotamos su nombre. Puesto que su núcleo es un verbo, se trata de un S.V. ¿Su función? Predicado: se relaciona con "los demás", que constituye su sujeto semántico (quienes han de respirar el aire puro son "los demás"); sintácticamente, el sujeto no se explicita por mediar un infinitivo "concertado" (el "de los demás" que figura en el texto funciona, como veremos, de complemento del nombre "derecho"). Como sujeto y predicado componen una sociedad indisoluble (está integrada por conceptos inherentemente correlativos: el sujeto lo es de un predicado, y el predicado lo es de un sujeto), cada vez que anotemos "Pred." en nuestro análisis hemos de tener identificado su sujeto (y viceversa). Cuando, como en este caso, no aparezca expreso ${ }^{7}$ en el texto, conviene reponerlo (encerrándolo entre paréntesis). Y la relación de interdependencia entre ambas funciones, a la que acabo de referirme, la precisamos con una flecha de doble punta:

7. No hay que confundir la falta de sujeto expreso con la falta de sujeto. Estructuras como Amanece a las siete; Hace frío; Hay pocas posibilidades; Se dice que va a haber movida / Dicen que va a haber movida son impersonales, es decir, carecen de sujeto; mientras que tengo prisa o la segunda coordinada copulativa de Acaban de llegar los representantes y dicen que va a haber movida tienen sujeto ( yo y los representantes, respectivamente) aunque no se explicite. En las estructuras impersonales sus sintagmas verbales no funcionan como predicado (¿de qué sujeto?); en cambio, los de las de sujeto implícito, sí. 
La libertad de fumar termina donde empieza el derecho de los demás a respirar aire puro

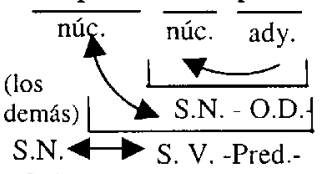

-Suj.-

PASO 5

En este punto de nuestro recorrido nos encontramos ante una construcción especial: un sujeto + un predicado, los constituyentes habituales de una oración. Pero está claro que esta construcción sintáctica no es una oración ${ }^{8}$, puesto que forma parte de un todo gramatical dentro del cual ejerce una determinada función, como una pieza más de su engranaje. A estas estructuras susceptibles de actuar como oraciones por poseer sus constituyentes típicos, pero que no se comportan como tales (son parte, no el todo) se les da el nombre, entre otros, de proposiciones ("prop."). Las que se hallan refuncionalizadas (o transpuestas), es decir, las que cumplen cualquiera de las funciones que en la oración simple se encomiendan a una palabra o a un sintagma (sujeto, objeto directo, adyacente...) se conocen como proposiciones subordinadas ("subda.").

La que nos ocupa ahora, respirar aire puro (los demás), pertenece a las subordinadas sustantivas: puede conmutarse por un sintagma nominal (la respiración / el respiro de aire puro) o por eso ${ }^{9}$ (el derecho de los demás a eso), posibilidad que cabe reflejar en nuestro diagrama de acuerdo con lo explicado en el paso 3. Desempeña la función de término de preposición ("T.") $)^{10}$ : la sola presencia de la preposición a lo evidencia.

La libertad de fumar termina donde empieza el derecho de los demás a respixai aire puro

8. Ante terminología tan diversa al respecto y, en particular, ante concepciones tan dispares de este término, he de manifestar que entiendo por oración lo que Bloomfield: "una forma lingüísticamente independiente no incluida en ninguna forma lingüística mayor en virtud de alguna construcción gramatical" (un comentario acertado sobre esta definición puede verse en LYONS, J., Introducción en la lingüística teórica, Barcelona, Teide, 1975 [3ae ed.], pág. 178). Se trata, por lo tanto, de la unidad sintáctica mayor, una unidad que no tiene función dentro de la sintaxis, sino fuera de ella, en la gramática textual.

9. Las subordinadas sustantivas son conmutables por eso por pura lógica: eso pertenece, como los sustantivos, a la categoría de primer rango (en terminología de Jespersen): es un pronombre sustantivo (no puede funcionar como adjetivo porque el español no cuenta con sustantivos neutros de los que depender); por eso, también los sintagmas nominales, no sólo las proposiciones, suelen admitir tal conmutación (Han leído los periódicos > Han leído eso; Comieron cerezas > Comieron eso...). Por razones de "corrección política" la conmutación chirría cuando el referente alude a personas (Quien espera desespera > *Eso desespera / Ese desespera, como Estoy viendo a tu amigo > *Estoy viendo eso / Estoy viendo a ése).

10. O la de C.N. mediante el índice funcional $a$, si se quiere. 
Las proposiciones subordinadas van introducidas por una especie de heraldo que avisa de que la estructura que presenta no consiste ya en una oración a pesar de que contiene los constituyentes típicos de ésta. Este "heraldo", por transponer construcciones oracionales preparándolas para el desempeño de funciones propias del sustantivo, del adjetivo, del adverbio, o de sus respectivos sintagmas, suele recibir la denominación de transpositor ("tr."). Los transpositores pueden ir expresados por una palabra ad hoc (las conjunciones y locuciones conjuntivas subordinantes) o incorporados en otra en perfecto sincretismo. En las oraciones Sé que llegarás a tiempo" o La situación empeorará a menos que alguien lo remedie, por ejemplo, que y a menos que son transpositores puros:
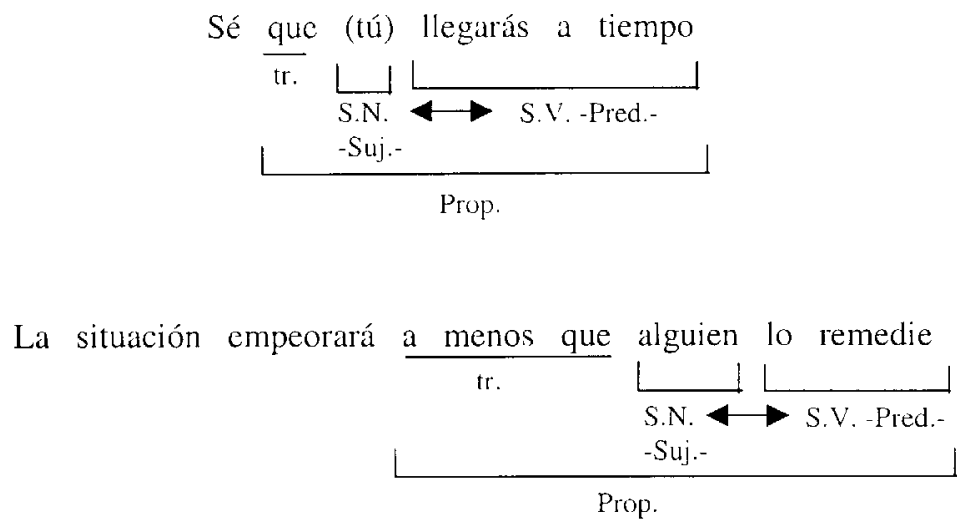

En cambio, las proposiciones de infinitivo, de gerundio y de participio no necesitan ir introducidas por un transpositor específico ${ }^{12}$ porque la sola presencia de cualquiera de esas formas verbales ya indica que se trata de una proposición subordinada ${ }^{13}$. Por eso, frente a Quiero que comas decimos Quiero comery no * Quiero que comer, o frente a Si tú estás conmigo, ya no tengo miedo cabe Estando tú conmigo, ya no tengo miedo, pero no *Si tú estando conmigo... Es decir, el morfema de estas tres formas verbales, cuando son nucleares, actúa como transpositor. Esto puede expresarse bien en el diagrama del análisis inspirándonos en lo que hace Jesús Tusón ${ }^{14}$ : rodeando con un círculo la desinencia correspondiente del que sale una línea horizontal por encima hasta llegar al primer lugar de la proposición (el de las conjunciones subordinantes, el de los transpositores, el de los "heraldos") y desde allí hacerla descender verticalmente escribiendo en su extremo "tr." (transpositor):

11. En esta estructura se percibe muy bien lo que hemos recordado sobre los conceptos de proposición y de transpositor: Llegarás a tiempo sería una oración si no fuera porque que la transpone al comportamiento propio de un S.N., de manera que ya puede funcionar como O.D. y deja de ser una oración, en consecuencia, para convertirse en proposición.

12. Otro tipo diferente de proposiciones que tampoco lo necesitan (las de relativo e interrogativas indirectas) lo veremos más adelante.

13. Efectivamente, no usamos estos "verboides" (en terminología de Lenz) como verbos de la oración ("verbos principales" en gramática tradicional). Ningún hispanohablante dirá, en lugar de Viene tu padre, *Venir tu padre (propio de los indios de las películas), *Viniendo tu padre o Venido tu padre. 14. Op. cit., pp. 206-208. 

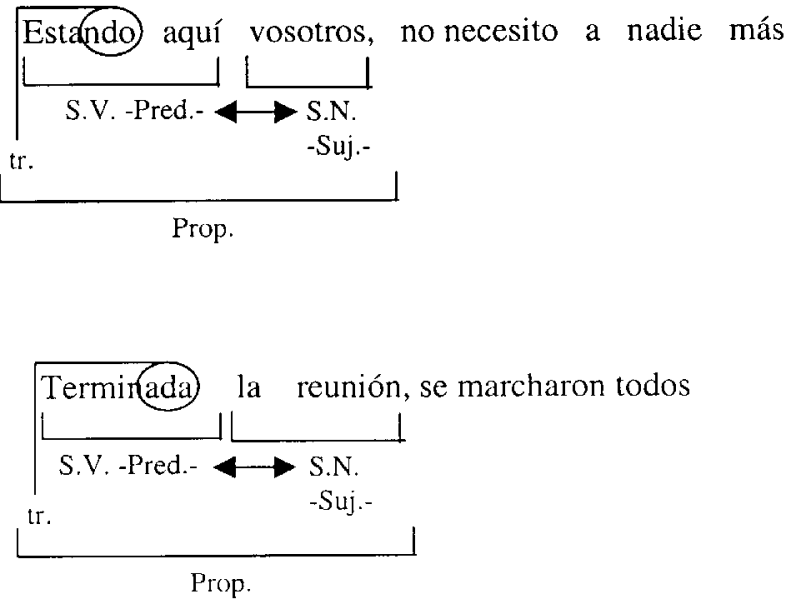

O la proposición respirar aire puro de nuestro texto.

\section{PASO 6}

Ya hemos visto que esta proposición subordinada sustantiva de infinitivo constituye el término de la preposición a. Junto con ella forma un sintagma preposicional ${ }^{15}$ que funciona como complemento nominal (C.N.), complemento del nombre o sustantivo "derecho"116. Efectuamos esta anotación y trazamos la flecha pertinente que apunte al núcleo ("derecho"):

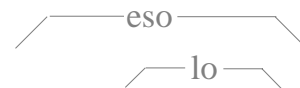

La libertad de fumar termina donde empieza el derecho de los demás a fespirâr aire puro

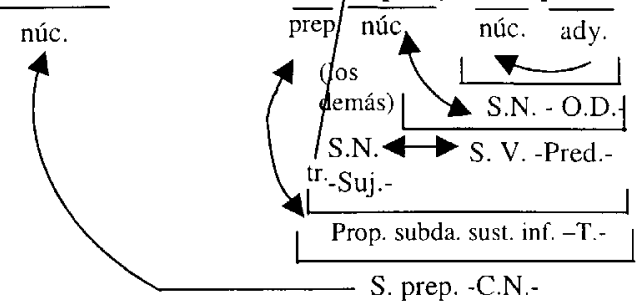

15. Unimos sus dos componentes con doble flecha por razones obvias: toda preposición exige un término y todo término de preposición requiere una.

16. La terminología de los adyacentes de núcleos no verbales se encuentra lejos de unificarse. Hay quien Ilama a todos "adyacentes"; quien, a todos "complementos"; quien, a todos "modificadores"... Otros disciernen los que van precedidos de preposición de los que no: "adyacente indirecto"/"adyacente directo"; "modificador indirecto"/"modificador directo"... Siguiendo esta última tendencia, nosotros Ilamamos adyacentes sin más a los elementos que dependen directamente de un núcleo, sin ningún tipo de enlace (como el roja de cinta roja o el muy de muy bueno o de muy bien), y complementos, con el apellido correspondiente al núcleo del que dependen, a los que lo hacen mediante una preposición; así, en los sintagmas la hija de tu primo, propenso a la melancolía y cerca de mi casa, de tu primo, a la melancolía y de mi casa son, respectivamente, complemento nominal, adjetival y adverbial. 
Y, como cada vez que trazamos una flecha así, nos hacemos la oportuna pregunta: ¿hay algún elemento más que dependa de este mismo núcleo? En este caso la respuesta es afirmativa: el determinante "el" (si, en lugar de "derecho", se hubiera escrito opción, por ejemplo, el artículo habría adoptado la forma la) y el sintagma preposicional (que habremos analizado previamente) "de los demás", que consta de la preposición "de" y del S.N. ${ }^{17}$ "los demás" (det. + núc.) y funciona como C.N. también.

Queda clara la marginalidad característica de los C.N. (y de los complementos y adyacentes en general): cualquiera de los dos podría omitirse (el derecho de los demás / el derecho a respirar aire puro), incluso ambos (el derecho), sin que se resintiera la gramaticalidad, sino sólo la información; lo que no ocurriría, en cambio, si suprimiéramos su núcleo (*donde empieza de los demás o *donde empieza a respirar aire puro). Al dibujar las flechas pertinentes observamos plásticamente que del núcleo "derecho" dependen el determinante "el" y los C.N. "de los demás" y "a respirar aire puro" (las de los tres convergen en él). Ya tenemos identificado, pues, otro sintagma, un gran S.N. puesto que abarca más de la mitad de las palabras del texto. Este S.N. cumple la función de sujeto ("Suj."): obliga a su verbo ("empieza") a concordar con él en número y persona; si cambiáramos su núcleo ("derecho") por derechos, automáticamente "empieza" se convertiría en empiezan (donde empiezan los derechos...).

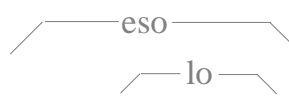

La libertad de fumar termina donde empieza el derecho de los demás a fespirár aire puro

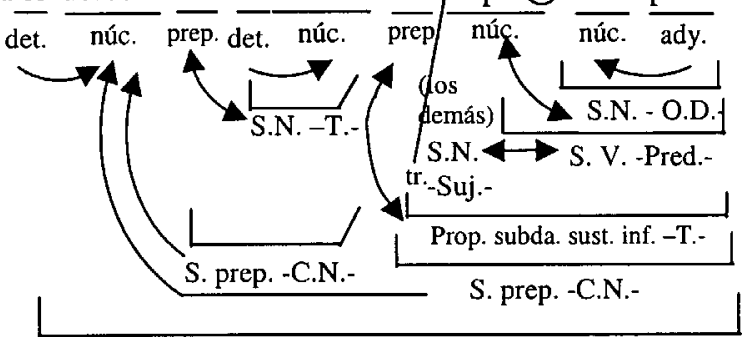

S.N.-Suj.-

PASO 7

El verbo "empieza" funciona como núcleo, ya que de él depende "donde". Los adverbios, como se sabe, o son adyacentes de un adjetivo o de otro adverbio, o complementan un verbo. A nuestro adverbio "donde" sólo le cabe esta última posibilidad. Equivale, aunque parcialmente, a allí, o a ahí, o a aquí, de los que se diferencia por el hecho de aglutinar un valor relativo (en el que luego me detendré) del que éstos carecen. Funciona como complemento circunstancial ("C.C."), igual que lo haría allí

17. En el sintagma "los demás" el pronombre indefinido demás, su núcleo, se revela como una categoría de primer rango, la de los sustantivos (hasta está determinado por un artículo). En la práctica del análisis sintáctico los pronombres sustantivos se asimilan a los sustantivos y, por tanto, sus sintagmas se consideran S.N.; no suele emplearse el término sintagma pronominal. 
en la frase El derecho de los demás... empieza allí. Lo anotamos y trazamos una flecha que apunte al núcleo, delimitamos "donde empieza" con la correspondiente bandeja, que rotulamos "S.V. -Pred.-", y unimos el sujeto y el predicado con flechas de doble implicación:

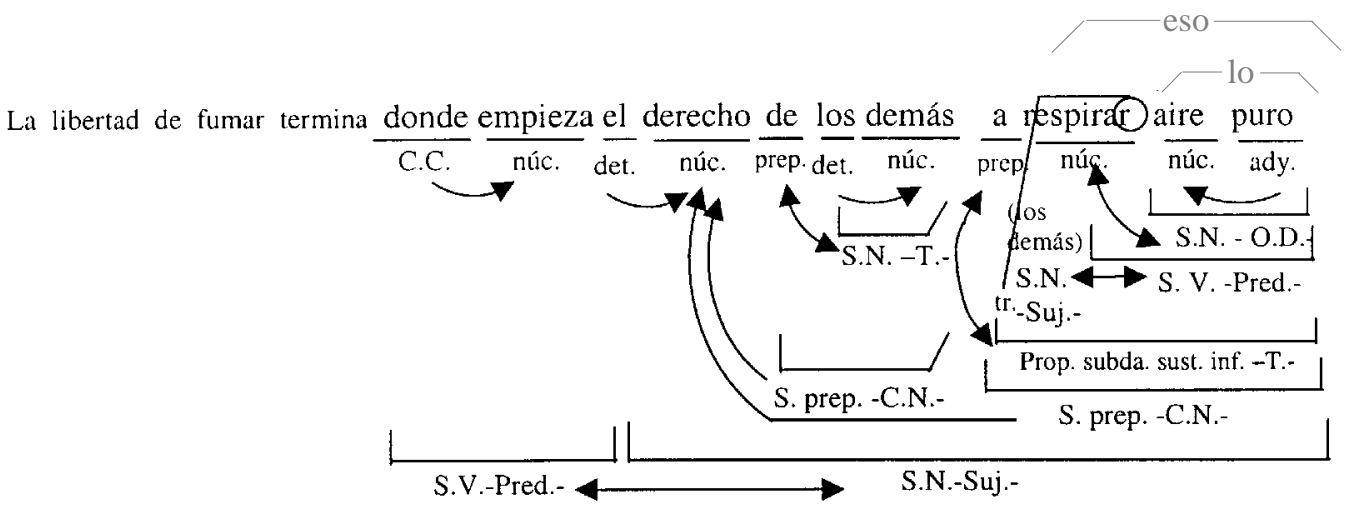

\section{PASO 8}

Como nos ocurrió en el paso 5, topamos ahora con una estructura que consta de los componentes típicos de la oración (sujeto + predicado), pero que, según nuestro criterio y por las razones allí expuestas, no lo es. Se trata, en consecuencia, de una proposición, de una subordinada adverbial en concreto: depende directamente de un verbo ("termina"), en relación de determinación, y, además, en este caso, puede conmutarse por un adverbio (allî), posibilidad que cabe reflejar en el eje paradigmático de nuestro diagrama según vimos. Funciona como funcionaría allí en La libertad de fumar termina allí, es decir, como C.C.: puede suprimirse sin que resulte agramatical la secuencia subsiguiente (La libertad de fumar termina) y sin que el verbo experimente un cambio semántico, sino, simplemente, con la lógica pérdida de la información que aporta.

Pero, como también expliqué en el citado paso 5, las proposiciones subordinadas van introducidas por un transpositor. ¿Y dónde está aquí ese elemento requerido? En el adverbio "donde", en sincretismo con los valores semánticos propios de los adverbios demostrativos (aquí, ahí, allí) que en el paso anterior hemos dejado dicho que subsume. Importa al respecto percatarse de la imposibilidad que tiene "donde" de aparecer en un lugar distinto del primero de su proposición (* La libertad de fumar termina empieza donde... o * Lo vi estuvimos donde nosotros / ${ }^{*}$ Lo vi estuvimos nosotros donde). ¿Por qué? Porque ése es precisamente el lugar que corresponde a las conjunciones subordinantes, a los transpositores puros (Quiero que vayas / ${ }^{*} Q u i e r o$ vayas que; Si vienes, lo pasarás bien / *Vienes si, lo pasarás bien). Nuestro "donde", por lo tanto, es una palabra bifuncional: por un lado, actúa como transpositor; por otro, funciona de acuerdo con su condición adverbial, según hemos señalado en el paso anterior. En el diagrama expresamos su función introductora-transpositora tirando una línea vertical descendente desde su extremo izquierdo bajo la cual anotamos "tr." de 
manera que resalte como primer componente de la proposición. Proposición que delimitamos mediante una bandeja que incluya sus tres componentes (transpositor, sujeto y predicado) y que rotulamos especificando su clase y su función.

allí

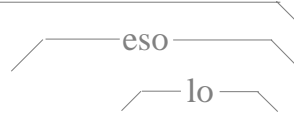

La libertad de fumar termina donde empieza el derecho de los demás a vespiri(1) aire puro

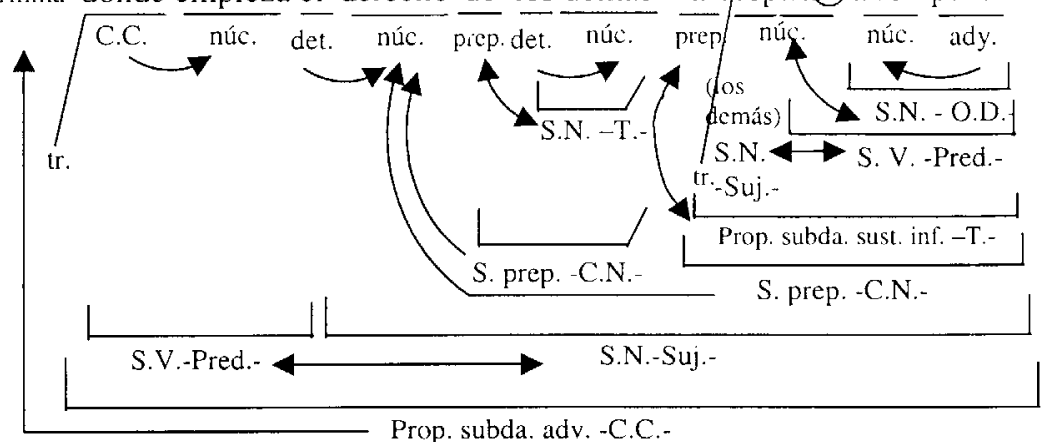

No constituye donde el único caso de palabra bifuncional aglutinadora de transpositor. Aparte de darse tal característica en las formas no personales del verbo (como ya expliqué a propósito de "respirar"), la encontramos de una manera semejante a la de donde en sus hermanos cuando, como (el modal) y cuanto, y en las categorías (pronombres, determinantes y adverbios) relativas e interrogativas indirectas, en cuyo análisis también hemos de tener en cuenta la bifurcación. Se trata de elementos que contienen lo que en gramática generativa se denomina refuncionalizador QU- ${ }^{18}$. He aquí algunas muestras:

No me gusta la película que habéis visto (vosotros)

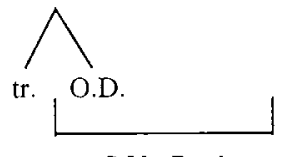

S.V. -Pred.-

Es un periódico cuyas hojas manchan mucho

18 Cf. al respecto la obra citada de Jesús Tusón, pp. 191-204. 


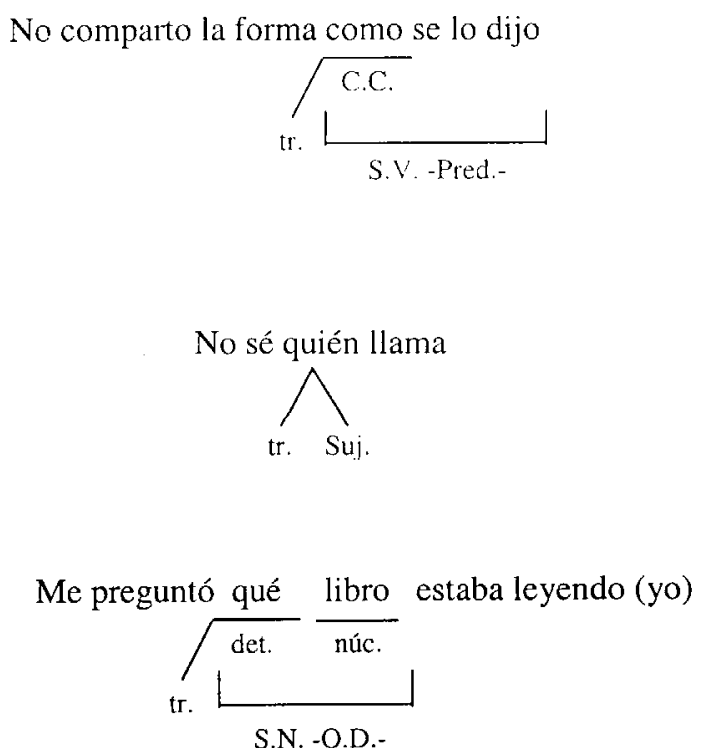

Debido a las leyes tectónicas del español, ocurre a menudo que un pronombre, determinante o adverbio de este tipo ha de ceder el primer lugar de la proposición a otra palabra (un adyacente suyo o una preposición). En tal caso, en el diagrama trasladaremos a la primera posición la faceta de transpositor que encierra mediante una línea que adelante por encima a sus elementos precedentes:

$$
\text { Sé muy bien } \underset{\text { de }}{\frac{\text { de dónde }}{\mathrm{T} .}} \text { lo has traído (tú) }
$$

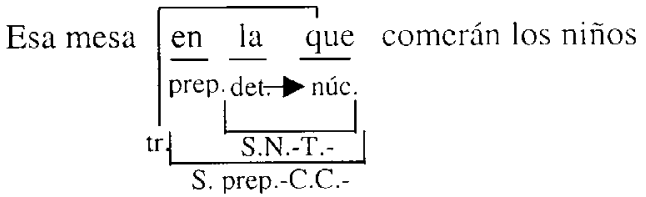

\section{PASO 9}

Dado que la proposición "donde empieza el derecho de los demás a respirar aire puro" funciona como C.C. de "termina", hacemos arrancar de ella una flecha que apunte a este verbo ${ }^{19}$. Y, como ningún otro elemento más depende de este núcleo, abarcamos los dos en una bandeja que contiene el S.V. -Pred.- de la oración:

19 Hay que abandonar para siempre (debió haberse abandonado hace mucho tiempo) la vieja y trasnochada dicotomía oración principal / oración subordinada. Su mantenimiento no sólo supone una 
La libertad de fumar termina donde empieza el derecho de los demás a espirá aire puro

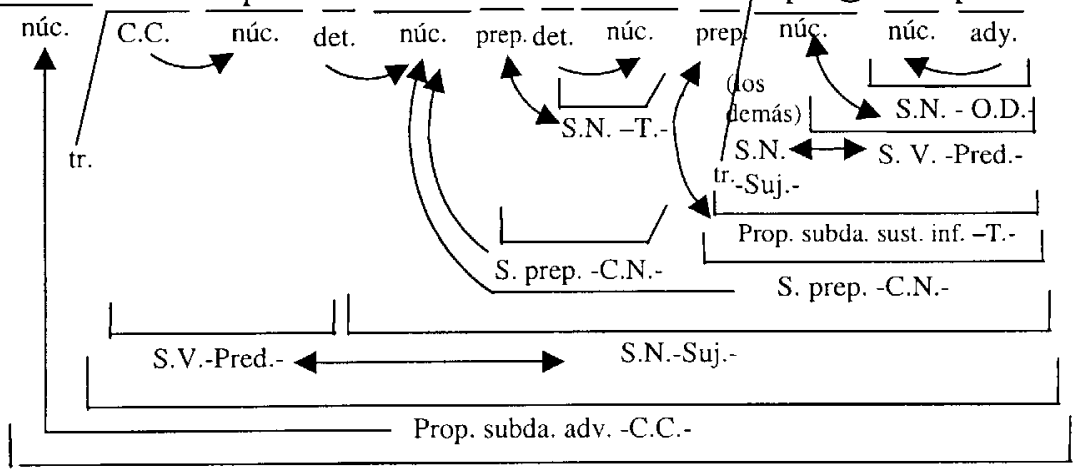

S.V. -Pred.-

PASO 10

El infinitivo "fumar", como el "respirar" analizado antes, engloba en su morfema la marca de transpositor, lo que expresamos en el diagrama de la manera explicada. No le colocamos la etiqueta "núc." porque ningún elemento depende de él; así que directamente anotamos "S.V.". Pero no le adjudicamos la función propia del S.V., la de predicado, porque (a diferencia de aquel "respirar") no se refiere a ningún sujeto, carece de sujeto semántico, se comporta como impersonal; y ya sabemos que sujeto y predicado son conceptos inherentemente correlativos.

Vemos cómo este verbo, transpuesto a elemento nominal por el transpositor comentado, constituye una proposición, una subordinada sustantiva que, evidentemente, funciona como término de la preposición "de". Con ella, en relación de interdependencia como indica la doble flecha, forma un sintagma preposicional con la función de C.N. del núcleo "libertad" y así lo reflejamos gráficamente con una flecha simple. Del mismo núcleo depende el determinante "La" y de igual manera gráfica lo expresamos.

Así que los tres elementos relacionados (núcleo, determinante y complemento nominal) componen un conjunto, un S.N. que funciona como sujeto del predicado ya analizado: el núcleo de éste ("termina") cambiaría automáticamente a terminan si sustituyéramos "libertad" por libertades.

antigualla, sino que (y esto es lo más grave) resulta contraproducente desde el punto de vista conceptual y desde el didáctico. Una proposición que, por ejemplo, desempeña la función de C.C. (como la del texto) o de O.D. forma parte de la estructura de un predicado y, por lo tanto, separarla de él conlleva artificio y contradicción. Afirmar que Luis quiere y que vayas en Luis quiere que vayas (o El camino empieza y donde termina la carretera en El camino empieza donde termina la carretera) son, respectivamente, la oración principal y la subordinada resulta tan falso como partir una manzana en dos trozos y empeñarse en ver en ellos dos manzanas (una principal y la otra secundaria). 
La libertad de fumar termina donde empieza el derecho de los demás a espirir aire puro

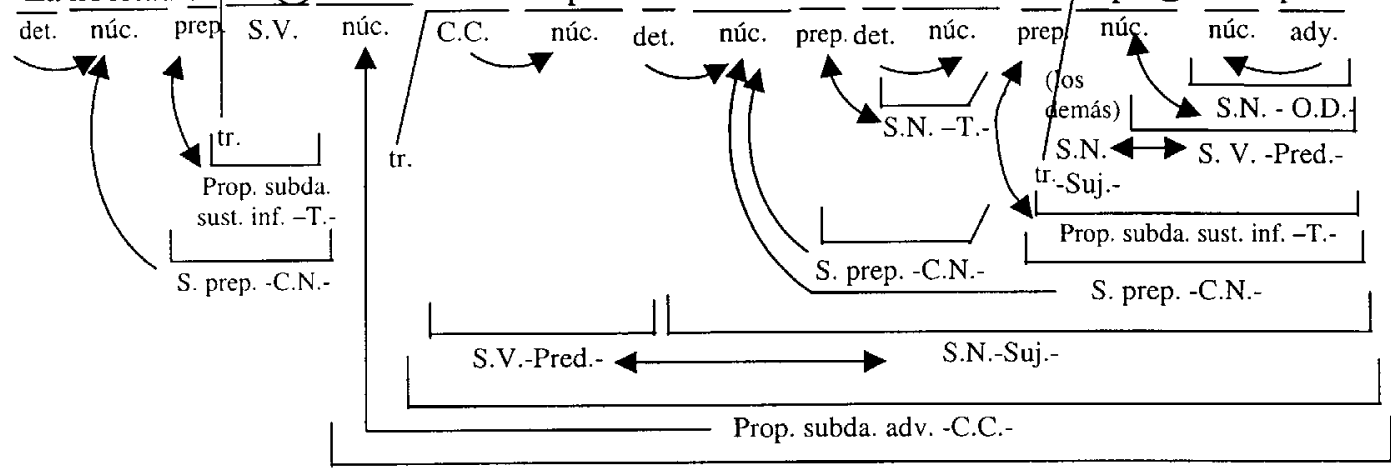

S.V. -Pred.-

PASO 11

Y ya sólo nos queda implicar mutuamente, mediante doble flecha, ambos sintagmas (el del sujeto y el del predicado) para expresar que, juntos, constituyen "una forma lingüísticamente independiente no incluida en ninguna forma lingüística mayor en virtud de alguna construcción gramatical", es decir, la oración.

La libertad de fumar termina donde empieza el derecho de los demás a espir(iT aire puro

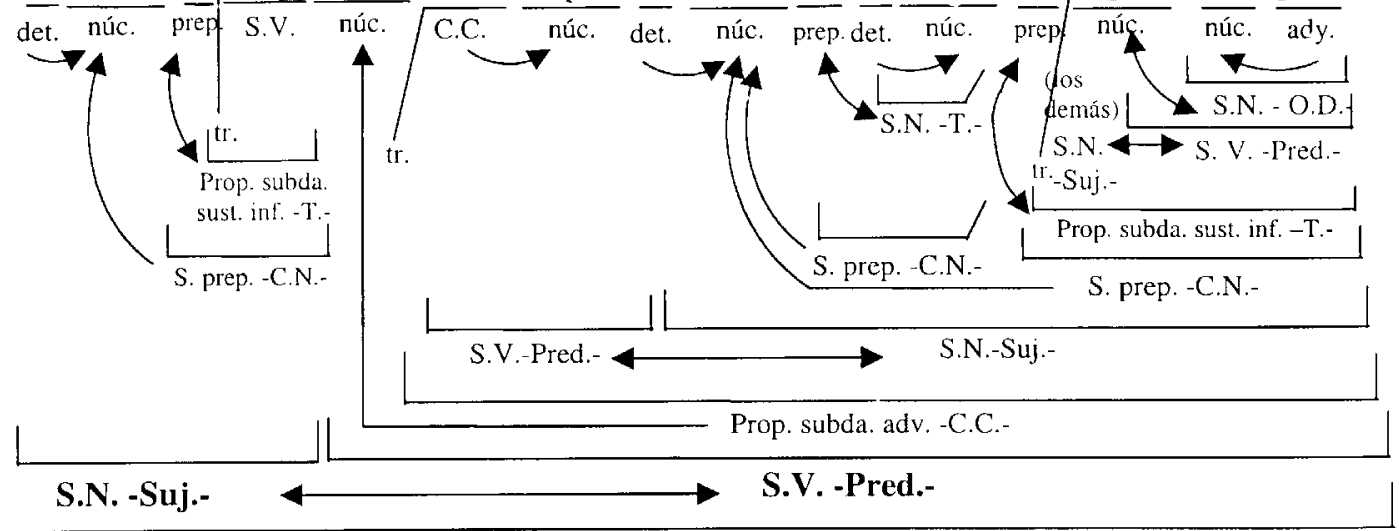

\section{Oración}




\section{Síntesis}

Los pasos que hemos ido dando y explicando en este trabajo han estado supeditados a la frase concreta seleccionada. Las fases comunes en el análisis sintáctico de cualquier texto pueden reducirse a tres: en la primera, se identifican las palabras gramaticales subrayándolas; en la segunda, se van agrupando sucesivamente de manera jerárquica esas palabras, de derecha a izquierda, para conformar los sintagmas correspondientes; en la tercera, se señalan los constituyentes inmediatos de la oración (generalmente, sujeto y predicado) y, en consecuencia, se identifica y delimita ésta.

\section{Bibliografía citada}

ALARCOS LLORACH, E. (1980). Estudios de gramática funcional del español. Madrid, Gredos (3 $3^{\mathrm{a}}$ ed.).

ALARCOS LLORACH, E. (1994). Gramática de la lengua española. Madrid, Espasa Calpe.

BOIX, A. et al. (1988). Práctica del análisis sintáctico. Barcelona, PPU (2ª ed.).

CARRATALÁ, E. (1980). Morfosintaxis del español actual. Barcelona, Labor Universitaria.

GARCÍA LÓPEZ, J. y PLEYÁN, C. (1969). Introducción en la metodología del análisis estructural. Barcelona, Teide.

GÓMEZ TORREGO, L. (1985). Teoría y práctica de la sintaxis. Madrid, Alhambra.

GÓMEZ TORREGO, L. (2002). Análisis sintáctico. Teoría y práctica. Madrid, SM.

GUTIÉRREZ, S., IGLESIAS, M. y LANERO, C. (2002). Análisis sintáctico 1. Madrid, Anaya.

HERNÁNDEZ, C. (1984). Gramática funcional del español. Madrid, Gredos.

LYONS, J. (1975). Introducción en la lingüística teórica. Barcelona, Teide (3ª ed.).

ROJO, G. y JIMÉNEZ JULIÁ, T. (1989). Fundamentos del análisis sintáctico funcional. Universidad de Santiago de Compostela.

TUSÓN, J. (1980). Teorías gramaticales y análisis sintáctico. Barcelona, Teide. 